\title{
Place Attachment and Views on Tree Management
}

\author{
Daria Paniotova-Maczka ${ }^{1 *}$, Piotr Matczak ${ }^{2}$ and Piotr Jabkowski ${ }^{2}$ \\ ${ }^{1}$ Faculty of Psychology and Cognitive Science, Adam Mickiewicz University, Poznań, Poland, ${ }^{2}$ Faculty of Sociology, Adam \\ Mickiewicz University, Poznań, Poland
}

Few studies have investigated relational environmental views of different stakeholder groups. In this study, we investigated how residents of rural and urban municipalities view the management of trees (who should decide about trees' removal - the landowner, or the municipality), which provides a various range of ecosystem services and the extent that place attachment as a relational variable affects these views. The analysis was based on 231 questionnaires conducted in two Polish municipalities: one rural (Nysa) and one urban (Racibórz). Data were analyzed using statistical methods including logistic regression models for analyzing factors impacting the main research question. Our investigation showed that both place attachment involving public good sentiments and the perception of ecosystem services provided by trees, that are related to private

\section{OPEN ACCESS}

Edited by:

Susana Alves,

Sapienza University of Rome, Italy

Reviewed by:

Doruk Görkem Özkan,

Karadeniz Technical University, Turkey

Lina Fusaro,

Institute for Bioeconomy, Italian

National Research Council, Italy

*Correspondence:

Daria Paniotova-Maczka

daria.paniotova@amu.edu.pl

Specialty section:

This article was submitted to

Environmental Psychology,

a section of the journa

Frontiers in Psychology

Received: 10 December 2020

Accepted: 23 April 2021

Published: 03 June 2021

Citation:

Paniotova-Maczka D, Matczak P and Jabkowski $P$ (2021) Place Attachment and Views on Tree Management.

Front. Psychol. 12:639830. doi: $10.3389 /$ fpsyg.2021.639830 interests significantly impacted views on tree management. In rural areas the opinion, that the municipality should decide to remove trees was positively associated with a place attachment. For residents of urban areas (Racibórz), the strength of place attachment was not related to the perception of tree removal, but it was related to the perception of trees' cultural benefits. We argue that considering psychological variables related to the tree management issues could help avoid conflicts.

Keywords: place attachment, ecosystem services, rural vs. urban, the decision of cutting off trees, landowner vs. municipality, relational values, trees management

\section{INTRODUCTION}

Trees are an essential part of the environment. They provide several ecosystem services (ES), which include the direct benefits that natural environment delivers to people and positively affects human well-being (Millennium Ecosystem Assessment, 2005; Haines-Young and Potschin, 2013). Three main types of ES are distinguished: (1) provisioning (e.g., a supply of fruits and nuts, wood, and leaves); (2) regulation and maintenance (e.g., a source of oxygen, protection against the wind, and a positive effect on health as by producing phytoncides - antibacterial substances released into the air by leaves, flowers or bark); and (3) cultural (e.g., space aesthetics, place of recreation, and strengthening interpersonal relationships). As such, ES secure livelihoods and quality of life for individuals and communities. Despite this, tree cover loss is observed, caused by development pressure especially in urban areas (Nowak and Greenfield, 2018, 2020). In rural areas, trees decline occurs due to the changes in agriculture practices and difficulties with trees management, planting, cultivation, and cutting off (Suchocka et al., 2019).

Since trees provide combinations of ES, for particular private individual and publicly for groups, their management is complex and can be organized and distinguished using two main tree management models. Firstly, public administration (municipal, regional, or national) 
has the decisive role and supports trees, forests and green areas as a public good, where all members of the community can benefit. Alternatively, individual owners assume that residents care for their own trees, gardens, orchards, and forests. They control and gain profits from their trees. They also contribute to public goods provision as their trees provide, for instance, scenic beauty that is valued by the community. Trees share characteristics of public goods. The theory of public goods suggests that leaving the management of public goods to individuals leads to under-provision (Mincey and Vogt, 2014). Common-pool resources are exhaustible and not prohibited from use (Schlager and Ostrom, 1992), which leads to their overexploitation. Therefore, regulations are imposed on human activities to define the property rights and rules of trees management in order to protect the environment. Public authorities (e.g., the municipality offices) need to take care of the green areas in order to secure the sustained provision of the public goods stemming from trees. In many countries, regulations concerning tree management on private land are in place, restricting tree removal by owners. Considering the complexity of ES provided by trees, these regulations need to count on residents' and owners' tree management views and motivations. Restrictions imposed on owners involve substantial trade-offs between the rights of a private owner and the need to sustain the quality of public goods. In Poland, the country of this study, forests' management is regulated by a specific law, defining the rights and obligations of the owners. This study concerns trees which are not part of the forests. The non-forest tree are also under the provision of the national regulation that specifies that a permit need to be obtained for removing trees in public (e.g., municipal) and private land. It does not apply to fruit and small trees but in most cases the permit to remove a tree is required. For most cases the permits are issued by the municipalities' administrations and involve compensation. This law was suspended for some month in 2017 igniting a discussion about tree protection and management.

A balance between residents' attitudes toward the ES and the regulations securing trees as public goods is an essential issue from both scientific and practical perspectives. Tree policies should account for peoples' tree-related values. The value of nature is conceptualized in several ways (Cundill et al., 2017). Nature is viewed dichotomously: via instrumental values (i.e., what we can "do" with what we have) and via the intrinsic values (i.e., what we consider essential). However, people rarely make choices using this simple distinction, and often consider both their relationship with nature and with others (Chan et al., 2016). This relationship is mediated through a variety of factors, including social norms, social cohesion, cultural identity, and policies (Díaz et al., 2015; Chan et al., 2016). These factors refer to the concept of relational values (Chan et al., 2018), which are "the values that are imbedded in desirable (sought after) relationships, including those among people and between people and nature" (Díaz et al., 2015; Stålhammar and Thorén, 2019). Relational values are not present in naturally occurring objects such as trees, but are the derivative of relationships to them. One of these relational values is place attachment (Cundill et al., 2017). People can look at nature differently depending on their emotional connection with nature. If nature is present directly next to their place of residence, then the emotional connection with the place of residence will include natural objects that are located directly on the territory of the residence. Place attachment can be an important factor that mediates individual views on trees management. For example, it motivates individuals to spend more time outdoors and to protect the landscape that is directly related to ES provided by trees. Relational values shape individuals' relationship with nature.

Although, relational values in the context of nature protection and sustainability are a topic of growing importance (Chan et al., 2018), these contributions are mostly conceptual (Knippenberg et al., 2018; Muradian and Pascual, 2018). De Vos et al. (2018) call for studies on the relational values of multiple, disaggregated stakeholder groups in their assessment, as it would help to highlight power imbalances and trade-offs in prioritizing relational values of various groups and subgroups.

In this paper, we address this need. Specifically, we look how place attachment can support an understanding of how two different groups of residents (rural and urban) differ in their view of the tree management. We investigated whether stronger place attachment is correlated with a preference for privateor public-led tree management. We also test whether views on tree management can be influenced by the demographic and environmental variables, such as the perceived benefit of trees. This study is the first investigation to address place attachment's influence on rural and urban views on tree management.

\section{LITERATURE REVIEW}

\section{Perception of the Benefits of Trees by Residents in Rural and Urban Areas and Involvement in Tree Management}

Recent research shows an unclear picture of resident views on tree benefits and tree management. In general, people who see the benefit of trees are more likely to feel responsible for managing trees, while people who think that trees create problems are not willing to participate in urban tree management (Moskell and Allred, 2013; Breger et al., 2019). Moreover, the perception of the benefits of trees depends on ES they provide (i.e., the attributes of trees). For example, trees that tend to fall or drop many leaves are perceived as less useful overall (Camacho-Cervantes et al., 2014; Fernandes et al., 2019). Nevertheless, people more often note the benefits of trees, rather than their drawbacks, and tend to prefer more trees in cities. Tree-related benefits are also more noticeable if a tree is closer to a house as the tree is perceived as a means of directly improving air quality. Abd Kadir and Othman (2012) identify three areas on which one can take advantage of trees: (1) the physical sphere (e.g., the reduction of the greenhouse effects, the purification of air from small polluting particles, the provision of shade, the surfaces shielded from electric breaks, the management of stormwater, the increase in property value, and the aesthetic beauty); (2) the social sphere (e.g., the benefits of trees are related to the security that trees can offer such as slower traffic on streets where trees are planted); (3) the economic sphere 
(e.g., trees on land increase the value of a house, due to benefits including shade, contributing to energy-savings, and reducing electricity bills. Few studies concern residents' tree management views in rural areas (Dei, 1992; Vermeulen, 1996). According to Chambers and Leach (1989), trees offer savings and security for the rural poor. Trees in rural areas, especially poor ones, play an essential role in providing resources and contributing to economic security. Trees can be a crucial economic resource. In India, trees are used to provide collateral when applying for a loan, so that if a person did not repay their loan, the bank could remove their trees valued equivalent to the loan amount and interest. Trees could also pay off loans and repay debts (Chambers and Leach, 1989). Therefore, it was the right to dispose of trees in the remote territory, that increased their creditworthiness, and protected natural disasters such as flooding. Studies have shown that people living in rural areas perceive trees as offering many positive and negative contributions (Blanco et al., 2020). The benefit of firewood was especially emphasized as a means to save energy costs. The importance of intangible ES, such as scenic value and originality of landscape as well as traditional land-use practices, was also noted. For example, villagers harvest firewood and collect fruits, nuts and mushrooms not only to meet material needs, but also to maintain certain traditional practices and social interactions. Of the negative ES, there is a physical obstacle to mechanization, the difficulty of matching mechanized agriculture with trees, which is associated with cutting down trees, and additional expenses associated with damage caused by trees.

These studies show that perceived tree benefits vary depending on the area. Nonetheless, the way in which these differences affect the views on tree management, including who decides on cutting trees, has not been investigated. Moreover, previous studies show that protecting natural objects such as trees or changing them (including cutting down) can lead to conflicts between the authorities and private landowners (Götmark, 2009; Devine-Wright and Howes, 2010).

\section{Place Attachment and Relational View on Nature}

Place attachment can be considered in three conceptual dimensions: (1) the personal dimension, where attachment to a place is considered in the context of the place's meaning; (2) the psychological dimension, where attachment includes an emotional, cognitive and/or behavioral component; and (3) the place dimension, where attachment to a given place is considered in the context of components and characteristics (e.g., social and physical) of that place (Brown and Raymond, 2007; Scannell and Gifford, 2010). Along with the concept of place attachment are the concepts of the significance of a place (Stedman, 2003; Jorgensen and Stedman, 2006), one's identification with a place (Hernández et al., 2007; Lewicka, 2008), and the dependence on a place (Trentelman, 2009). Some studies also consider three concepts as predictors of the sense of a place (Jorgensen and Stedman, 2006). Place attachment is also viewed as an integral part of identification with a place (Low and Altman, 1992; Twigger-Ross and Uzzell, 1996; Mazumdar et al., 2000; Stedman, 2002). In this study, we focused on an emotional connection with the place for three primary reasons. Firstly, it is a component of the psychological dimension of place attachment. Secondly, the emotional component is the strongest indicator of attachment. Finally, the emotional component of place attachment is often a component in other approaches that explains a person's relationship with a place, such as identification with a place and the meaning of a place (Perkins and Long, 2002; Lewicka, 2008).

We assume that attachment to a place can indirectly influence tree management opinions. Attachment to place is also a manifestation of a relational view of nature and contributes to the development of relational connections with nature. This connection appears primarily as the interest in nature. It is a responsibility for nature and care for it. Since attachment to a place can be of different strengths, these relationships will consequently display various strengths. Some social and demographic factors, such as house ownership, length of stay in one locality, age, gender, education, and income (Anton and Lawrence, 2014) can be predictors of the place attachment strength. A sense of local community and local social contacts (Buchecker and Frick, 2020) are also predictors of stronger place attachment.

Research suggests that, in general, people living in rural areas are more firmly attached to their places of residence than are people living in urban areas (Lewicka, 2011; Anton and Lawrence, 2014; Verbrugge and van den Born, 2018). Gosling and Williams (2010) argue that a connection with nature plays a significant role in preserving green spaces in rural areas among farmers. Those farmers who felt a greater connection with nature were inclined to preserve trees on their territory. There are several predictors of place attachment strength, such as owning one's own home and their type of settlement. These factors are correlated with views on tree management.

\section{Place Attachment and Involvement in Activities Related to the Place}

Previous studies show that place attachment can play a key role in shaping attitudes toward planning a change of place, an interest in managing a place, and involvement in its affairs (Davenport and Anderson, 2005; Walker and Ryan, 2008; Buta et al., 2014; Van Veelen and Haggett, 2016). However, there is a lack of knowledge surrounding the connection between place attachment's strength and preferences concerning the environment (e.g., concerning views on tree management). On the one hand, studies (Mohapatra and Mohamed, 2013) show that, the people who have a stronger place attachment more often support of pro-environmental measures in relation to natural objects (e.g., parks). On the other hand, a stronger place attachment can contribute to supporting the status quo of a place and is a cause of resistance to changes associated with a place (Devine-Wright and Howes, 2010; Bonaiuto et al., 2016). This divergence may be due to two main factors: services provided by the place and the rural or urban location. The difference in the perception of the services provided by the place influences the strength of place attachment and can play a key role in shaping preferences around tree removal decisions. 
Studies on place attachment and involvement in the management of these places carried out in urban areas, concerning parks, squares, and city forests, show that people who are more attached to natural places willingly support nature conservation when a natural place is their place of recreation, psychological restoration, or a setting for sports (Mohapatra and Mohamed, 2013). In rural areas, landscapes, including trees, are often perceived as an economic resource that provides residents with certain benefits. Previous studies in rural areas show that a high level of place attachment and a high level of positive attitude toward landscapes was a significant obstacle to planned changes to landscapes. When individuals are comfortable with a place, they do not support change to that place (Park and Selman, 2011; Chappell et al., 2020). Studies by Walker and Ryan (2008) show a strong positive correlation between attachment to the rural landscape and support for activities aimed at protecting agricultural soils. In urban environments, residents tend to support landscape changes if they are of benefit (Von Wirth et al., 2016). In general, changes are more opposed in the countryside than in urban areas. In rural areas, people are reluctant to support change that threatens their identity or limits their economic opportunities. Cutting down trees means a change in place and landscape. Therefore, place attachment will influence the perception of place change, and in the present case, place attachment impacts the perception of tree removal.

Previous studies also show that different place attachment includes support for specific changes. Inhabitants of rural areas who have recently moved to an area are reluctant to support changes in the social and economic sphere (e.g., community selfsupport, availability of shops), however, they support changes in the natural environment (place-protective behavior). Conversely, inhabitants who live longer in an area do not support changes in the natural environment, and instead support social and economic changes (Zwiers et al., 2018).

\section{The Conceptual Model of the Study}

In this study, we verify the impact of perceived ES provided by trees on views regarding preferred type of tree management, specifically who should decide about tree removal on a private land: the owner or the municipality. We treat place attachment as a moderating variable. Moreover, rural vs. urban municipality type was considered a factor influencing both place attachment and the perceived benefits of trees. Finally, possession of trees is considered a variable that may influence the perception of benefits and the preferred type of tree management. The research model is shown in Figure 1.

Place attachment (PA) is a latent construct understood as a respondent's bond to the place of residence. The perceived benefit of trees (ES) is understood as a declared respondent's tree-derived utility. Moreover, rural and urban areas (RurU) denote respondents' place of living in the village or the city. Finally, the variable who (i.e., whether the owner or the municipality should decide about tree removal; WHO) denotes the expected decision-maker.

We have established the following hypotheses:

H1. People living in urban/rural areas differ in the perceived benefits of trees. Specifically, people living in rural areas prefer provisioning benefits of trees, while people living in urban areas prefer those that are cultural.

H2. People living in rural areas are characterized by stronger place attachment compared to people living in urban areas.

H3. People who are more attached to a place perceive more benefit from trees than people who are less attached.

H4. People living in rural areas support the opinion that the owner should decide to remove trees from the land.

H5. In rural areas, support for the opinion that the municipality should decide about tree removal is positively associated

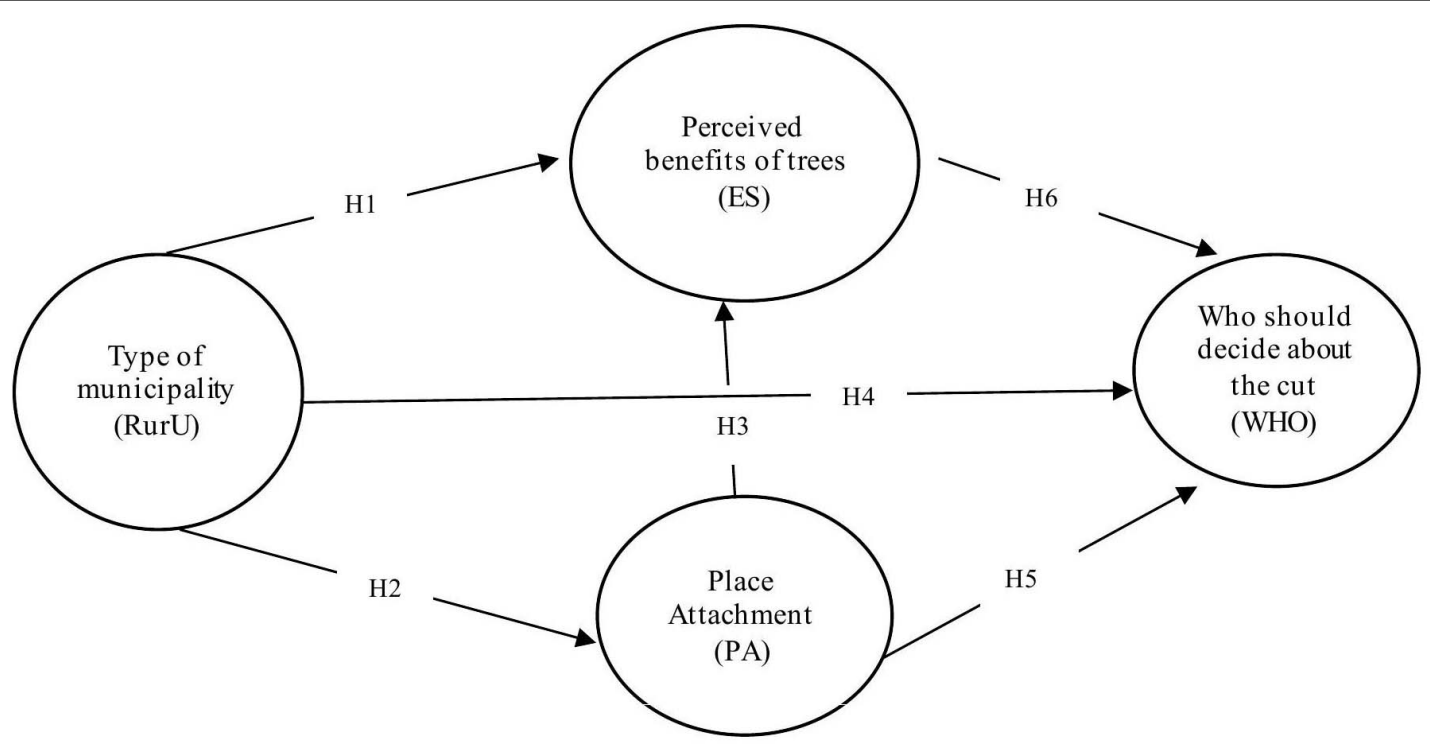

FIGURE 1 | The conceptual model of the study. 
with the place attachment and negatively associated with provisioning benefits of trees.

H6. In urban areas, supporting the opinion that the municipality should decide about tree removal is positively correlated with the place attachment and the perception of cultural benefits of trees.

\section{MATERIALS AND METHODS}

\section{Sampling Characteristics}

We surveyed respondents in two Polish municipalities, Racibórz and Nysa, in June 2019. The municipalities were selected purposively, as Racibórz is urban, and in Nysa we collected data only in the rural areas. Racibórz (55 thousand inhabitants) and Nysa (58 thousand inhabitants) represents medium size Polish municipalities. They were selected as "typical" in terms of greenspace coverage.

Data were collected via computer-based website questionnaires (CAWI). Respondents were asked to indicate trees that are relevant to them on the map of their municipalities, and to attribute ES to the trees they had indicated. Indicated trees could be both in private and in public land and ES were attributed to each tree separately. One or more ES could be attributed to a tree. Respondents were then asked to answer the question of who should decide about tree removal in private land. The information on the survey was advertised in mass media and the web pages of both municipalities. However, due to an insufficient number of completed questionnaires in Nysa, we also carried out face-to-face interviews. In these cases, the respondents filled in the questionnaire on laptops provided by a researcher (CAPI). After eliminating questionnaires with missing responses, a total of 231 questionnaires were included in the analysis (135 from Racibórz, 96 from Nysa). Table 1 provides information about the socio-demographic profile of respondents.

\section{Dependent Variable}

Our dependent variable includes answers to the question: "Who should decide about tree removal on private land?," with three

TABLE 1 | Sample distribution of respondents' socio-demographics.

\begin{tabular}{lcc}
\hline Demographic & Frequency & Percent \\
\hline Gender & 96 & 40.7 \\
Male & 140 & 59.3 \\
Female & & \\
Age & 37 & 15.7 \\
Up to 20 & 52 & 22.0 \\
$21-30$ & 55 & 23.3 \\
31-40 & 32 & 13.6 \\
$41-50$ & 60 & 25.4 \\
51 and older & & \\
Level of education & 19 & 8.1 \\
Primary & 38 & 16.1 \\
Secondary & 79 & 33.5 \\
Post-secondary & 98 & 41.5 \\
Higher & &
\end{tabular}

options for respondents to select: (i) the landowner; (ii) the municipality office or other offices, depending on the purpose of removal; and (iii) the landowner, except in specific situations questionnaire is attached together with the data set $<$.

\section{Independent Variables: Covariates and Factors}

The following independent variables were included in the analysis: (1) the type of municipality (a binary variable: rural/urban); (2) place attachment (measured by a latent variable that determines the strength of an emotional connection with the place of residence, $\alpha=0.869$ ). For the purposes of the study, we took the scale by Lewicka (2011), which consists of nine questions about people's feelings toward their place of residence. Participants replied to how much they agree with a given statement (e.g., "I miss the place when I am not here"). These response options ranged from one to five and indicate the strength of respondents' feelings about the place of residence questionnaire is attached together with the data set; and (3) perceived benefits of trees, where respondents chose one or more of 18 ecosystem services indicating benefits brought by trees that they pointed out on the map (a binary variable: yes/no). Three types of ES were also considered in the analysis: (1) provisioning (fruits and nuts, economic benefits, timbers, branches and leaves); (2) regulation and maintenance (wind protection, noise control, positive effects on health and wellness, animal habitat and food source, air and soil humidification, air purification, snowdrifts, sun protection); and (3) cultural (tree as a witness to cultural history, contribution to the aesthetics of space, educational usefulness, a sense of intimacy provision, separating from neighbors, strengthening interpersonal bonds, and recreation space). We relied on earlier studies and compiled a preliminary list of ES relevant to trees. It was included to the questionnaire, which was further tested. Eventually, $18 \mathrm{ES}$ were mentioned and the option "other" was also available. Indicated trees could be both on private and on public land and ES were attributed to each tree separately. Furthermore, we included in the questionnaire additional variables such as possession of trees and demographic characteristics of respondents (e.g., gender, age, and level of education).

\section{Statistical Procedures for Data Analysis}

All statistical procedures implemented in this study have been documented in the replication syntax file provided in the online supplementary materials; hence we do not describe here all the procedures implemented in the paper, especially those wellknown like $t$-test, Pearson correlations or linear regression analysis. We only specify logistic regression models for analyzing factors impacting on the view on who should make decisions about tree management.

We start with dichotomizing the dependent variable by merging two separate categories of respondents who indicated that "only owner" or "owner except in specific situations" should decide to remove trees. This decision was made due to very few cases in which respondents selected the latter category. Next, we specified a Logistic Regression model to explain 
the relationship between the dependent variable (who should decide about tree removal) and a subset of the independent variables (place attachment (PA), perceived benefits of trees: provisioning (ES1), regulation and maintenance (ES2), cultural (ES3), municipality type (rural/urban; RurU). However, we found collinearity between the two independent variables "regulation and maintenance" and "cultural". Therefore, we finally conducted the regression analysis using only two variables concerning ES1 and ES3. We also controlled for gender and age.

A detail specification of the regression model is as follows. Let us denote by $T R E E_{i}$ an outcome dichotomous variable, where $E\left(T R E E_{i}=1\right)=\pi_{i}$ is the probability of indicating by respondent $i$ that municipalities should decide on cutting down trees. We used a logit link function (based on the natural logarithm), where (1) the logit coefficient ${ }_{i}=\log \left(\frac{\pi_{i}}{1-\pi_{i}}\right)$ is the log of the odds of the event $T R E E_{i}=1$ as opposed to $T R E E_{i}=0$. We ran two logistic regression models: Model 1 with the vector of regression coefficients to assess the impact of particular covariates on the probability of indicating that municipality should decide on cutting down trees; and Model 2 with interactions to assess whether the impact of the rural/urban place of living on tree management views is mediated by other covariates. The specification of Model 1 is as follow:

$$
\begin{aligned}
n_{i}= & \beta_{0}+\beta_{1} \operatorname{Rur}_{i}+\beta_{2} \text { gender }_{i}+\beta_{3} \text { age }_{i}+\beta_{4} P A_{i}+ \\
& \beta_{5} E S 1_{i}+\beta_{6} E S 3_{i} .
\end{aligned}
$$

The regression equation for Model 2 is in turn as follows:

$$
\begin{aligned}
n_{i}= & \beta_{0}+\beta_{1} \text { Rur }_{i}+\beta_{2} \text { gender }_{i}+\beta_{3} \text { age }_{i}+\beta_{4} P A_{i}+\beta_{5} E S 1_{i}+ \\
& \beta_{6} E S 3_{i}+\beta_{7} \text { RurU }_{i} * P A_{i}+\beta_{8} \text { RurU }_{i} * E S 1_{i}+ \\
& \beta_{9} \text { RurU }_{i} * E S 3_{i}
\end{aligned}
$$

where:

$\circ \beta$ is a vector of regression coefficients.

In general, we looked for factors impacting the view on who should make decisions about tree management, and we also consider whether the impact of the type of municipality is mediated by other variables.

\section{RESULTS}

The perceived benefits of trees' provisioning services are valued less by the residents of Raciborz $(M=0.094, \mathrm{SD}=0.21)$ than by the residents of Nysa $(M=0.28, \mathrm{SD}=0.26)$. The difference is statistically significant when univariate $t$-test was used to analyse the difference $(t=5.65, p<0.001)$, and remained significant after controlling for gender and age $(t=5.49, p<0.001)$. The difference between the residents of Racibórz $(M=0.33$, $\mathrm{SD}=0.24)$ and Nysa $(M=0.32, \mathrm{SD}=0.28)$, in terms of the perception of cultural benefits from trees did not reach significance $(t=0.22, p>0.05)$. Therefore, concerning the hypothesis $1(\mathrm{H} 1)$ - "People living in urban and rural areas will differ in perceiving the benefits of trees. People living in rural areas prefer (1) provisioning benefits of trees, while people living in urban areas prefer those that are (2) cultural ones," our analysis shows that the difference in perception of ES by the residents of two municipalities is partially confirmed. The average value of the strength of place attachment is lower among the inhabitants of Racibórz $(M=0.65, \mathrm{SD}=0.79)$ than among the inhabitants of Nysa $(M=1.22, \mathrm{SD}=0.84)$. The analysis shows that the difference is statistically significant both for univariate analysis $(t=5.22, p<0.001)$ and after controlling for gender and age $(t=4.15, p<0.001)$. Concerning the hypothesis 2 (H2) - "People living in rural areas are characterized by stronger place attachment comparing to people living in urban areas" our analysis shows that the difference in the strength of place attachment of the residents of two municipalities fully confirmed.

A Pearson's correlation and partial correlation controlling for gender and age was performed to examine the relationship between the level of place attachment and the level of perceived tree benefits. The results show that the relationship between the level of place attachment and the level of perceived tree benefits is statistically significant for the provisioning benefits of tress (correlation coefficient: $r=0.19, p<0.05$; partial correlation coefficient: $r=0.18, p<0.05)$. The relationship between the strength of place attachment and the perception of cultural benefits of trees was not statistically significant $(r=0.07, p>0.05)$. Thus, concerning the hypothesis $3(\mathrm{H} 3)-$ "People who are more attached to a place (strength of place attachment) will see more benefits from trees than people who are less attached" our analysis shows that the relationship between strength of place attachment and perceived benefits from trees is partially confirmed.

The analysis also confirmed that the residents of Nysa more often support the opinion that the decision to remove trees should be made by the owner of the territory (78.1\%) compared to the residents of Racibórz (56.2\%). The difference is statistically significant (Fisher's Exact Test $=0.001$ ). Therefore, concerning the hypothesis $4(\mathrm{H} 4)$ - "People who live in the rural areas more often than those living in urban areas prefer that the owner of the territory on which the tree grows should decide on the cutting of the tree," our analysis shows that the difference in preferences about who should decide on the cutting of the tree of residents in two municipalities is confirmed.

However, the question arises whether the difference between rural and urban municipalities are still significant in this respect when we control for gender, age, place attachment, culturaland provisioning benefits of trees. Thus we applied a logistic regression models in accordance with the specifications outlined earlier in the paper to determine factors influencing the opinion of Racibórz and Nysa inhabitants about who should decide to remove trees; the municipality or the owner of the land.

Concerning the fifth and the sixth hypotheses, (H5) "In rural areas, support for the opinion that the municipality should decide about tree removal is positively associated with the place attachment and negatively associated with provisioning benefits of trees," (H6) "In urban areas supporting the opinion that the municipality should decide about tree removal is positively related with the place attachment and the perception of cultural benefits of trees" our analysis shows the mixed results. 
Firstly, the results of both regression models demonstrate that, in general, the opinion that the municipality should decide to remove trees is positively associated with the perception of the cultural benefits of trees (Model 1: $B=1.34, p<0.05$; Model 2: $B=2.17, p<0.05$ ) and negatively associated with the perception of the provisioning benefits of trees (Model 1: $B=-2.4, p<0.05$; Model 2: $B=-1.47, p>0.05)-$ Table 2. However, there are no differences between rural and urban municipalities in this respect which is demonstrated by a non-significant effect of interactions between the type of municipality and cultural and provisioning benefits of trees. On the other hand, the positive effect of interaction between type of municipality (Rural $=1$ ) and place attachment in Model $2(B=0.97, p<0.1)$ supports the hypothesis that in rural areas opinion that the municipality should decide about tree removal is positively associated with the place attachment. Note that gender and age of respondents have no significant impact on the opinion on who should decide to cut down trees.

\section{DISCUSSION}

Our study brings insights into a relational view of nature, manifested via place attachment. We tested whether place attachment could be a significant indicator of the opinion about tree management, and specifically on the issue of who should decide to remove trees residents or - the municipality.

Our results support the results of previous findings, that the rural/urban distinction has a significant impact on perceptions surrounding tree management (Jones et al., 2013; Blanco et al., 2020). Residents of the rural area (the municipality of Nysa), more often support the opinion that the owner of the land should decide about tree removal compared to residents of the urban area (the municipality of Racibórz).
The impact of the rural/urban place of living on tree management views is mediated by place attachment. In the rural area (Nysa), a stronger emotional connection with the place of residence implies residents' support municipalities deciding to remove trees. This may be due to the fact that a stronger place attachment in a rural area creates a greater sense of security and, as a consequence, a stronger trust in local authorities (Verbrugge and van den Born, 2018; Song et al., 2019; Peng et al., 2020), however, as we did not explicitly test this reasoning through our study, this offers an opportunity for future research. However, stronger emotional connections to the place of residence within urban area (Racibórz) does not lead to more support for the municipality's decisions to remove trees.

Our study results regarding the difference in place attachment's strength between rural and urban inhabitants are consistent with previous studies, indicating a tendency of greater emotional place attachment of rural inhabitants (Anton and Lawrence, 2014). Apart from this, our study results show that people who have greater strength attachment to their place of residence perceive more benefits from trees in terms of provisioning benefits of trees, regardless of the type of locality (rural vs. urban). In general, this is somewhat consistent with previous research that shows that a generally greater sense of place, identification with a place, and attachment to objects of nature increases involvement in activities about that place and increases interest in that place (Ryfield et al., 2019; Faccioli et al., 2020). Therefore, it can be assumed that people who have a higher place attachment see more benefit from the place and will be more likely to get involved in the place's affairs. More substantial involvement in these affairs can be associated with more interest in changes of place. However, how such a tendency would apply to the formation of an opinion about who should decide about tree removal remains to be investigated in further research. Besides, investigate the relationship between the strength of place attachment (identification with a place,

TABLE 2 | Logistic regression results.

\begin{tabular}{|c|c|c|c|c|c|c|}
\hline \multirow[t]{2}{*}{ Covariates } & \multicolumn{3}{|c|}{ Model 1} & \multicolumn{3}{|c|}{ Model 2} \\
\hline & B & SE. & $\operatorname{Exp}(B)$ & B & SE. & $\operatorname{Exp}(B)$ \\
\hline RurU: Type of municipality (Rural = 1) & -0.562 & 0.384 & 0.570 & -0.775 & 0.845 & 0.461 \\
\hline Gender of the respondent $($ Male $=1)$ & 0.461 & 0.324 & 1.602 & 0.384 & 0.333 & 1.468 \\
\hline Age & -0.018 & 0.012 & 0.982 & -0.018 & 0.012 & 0.982 \\
\hline PA: Strength of the place attachment & 0.225 & 0.200 & 1.251 & -0.081 & 0.247 & 0.923 \\
\hline ES1: Perceived benefits of trees: provisioning & $-2.384^{\star}$ & 0.837 & 0.092 & -1.466 & 1.108 & 0.231 \\
\hline ES3: Perceived benefits of trees: cultural & $1.337^{*}$ & 0.654 & 3.806 & $2.166^{\star}$ & 0.884 & 8.724 \\
\hline RurU * PA & & & & $0.965^{\wedge}$ & 0.531 & 2.625 \\
\hline RurU * ES1 & & & & -2.067 & 1.737 & 0.127 \\
\hline RurU * ES3 & & & & -1.867 & 1.414 & 0.155 \\
\hline Constant & -0.798 & 0.730 & 0.274 & -0.778 & 0.787 & 0.459 \\
\hline \multicolumn{7}{|l|}{ Fit statistics } \\
\hline -2 Log-likelihood & \multicolumn{3}{|c|}{254.387} & \multicolumn{3}{|c|}{246.766} \\
\hline Nagelkerke R Square & \multicolumn{3}{|c|}{0.158} & \multicolumn{3}{|c|}{0.200} \\
\hline Hosmer and Lemeshow Test & \multicolumn{3}{|c|}{$x^{2} 6.4 ; d f=8 ; p=0.602$} & \multicolumn{3}{|c|}{$\chi^{2} 5.7 ; \mathrm{df}=8 ; p=0.678$} \\
\hline
\end{tabular}

$\wedge p$-value $<0.1 ;{ }^{*} p$-value $<0.05$. 
attachment to the landscape) and openness to landscape changes in the case of trees removal (Walker and Ryan, 2008; Von Wirth et al., 2016; Verbrugge and van den Born, 2018). Future research may also check whether place attachment is related to the sense of trust of the administration that operates in a given place and how it is applied to the formation of an opinion about who should decide on tree removal.

Another mediating variable was the perception of ES provided by trees. Our research shows that the inhabitants of urban and rural areas differ in terms of the perception of the benefits provided by trees. The rural area inhabitants (Nysa) perceive the benefits from trees more in terms of provisioning than the inhabitants of the urban area (Racibórz). This is inconsistent with the previous results, where urban inhabitants valued provisioning ES and rural residents valued regulating ES (Yang et al., 2019). The same study by Yang et al. revealed the lack of differences between urban and rural residents concerning the perception of cultural benefits of trees. The differences between our study and the Yang et al.'s may result from the cultural, landscape, climatic and spatial differences between rural and urban areas in Poland and China. However, checking this would require further and more extensive research.

In general, the opinion that the municipality should decide to remove trees is positively associated with the perception of trees' cultural benefits and negatively associated with the perception of the benefits of providing resources from trees. However, in this respect, there is no difference between rural and urban municipalities.

Both place attachment involving public good sentiments and the perception of ES provided by trees that are related to private interests significantly impacted views on tree management. The factors reflect two overall trends. In rural areas (Nysa), the opinion that the municipality should decide to remove trees is positively associated with a place of attachment. For residents of urban areas (Racibórz), the strength of place attachment was not related to the perception of tree removal, but it was related to the perception of trees' cultural benefits.

Living in rural or urban areas reflects a difference in views on tree management. There is a higher degree of place attachment in rural areas, more perceived ES provisioning, and a stronger view that landowners should decide about tree removal. Those in rural areas that perceive the provisioning benefits of trees tend to support the view that the landowner should decide to cut down trees. Trees that are useful in bearing fruit and providing wood strengthen opinions that owners may reject the municipality interfering in tree removal decisions. This suggests that trees' instrumental value is essential for residents in rural areas who see more provisioning benefits from trees.

Our research also shows the instrumental value of the trees and that the hidden relative values are important in shaping opinions surrounding who should decide to remove trees. These values can reinforce a relationship with the natural components of the environment and influence views regarding the management of natural properties, especially in rural areas.

Our research has some limitations. The first is lack of measurement of surrounding attachments to particular natural objects located directly in the territory of a person's residence.
Future research addressing tree removal views, need to look directly at attachments to natural objects such as trees or other elements of landscapes (Blanco et al., 2020). The second limitations is that we examine emotional attachment only to the place of residence. Further research should examine not only the strength of emotional attachment to one's place of residence in forming an opinion about who should decide on tree removal but also attachment to vegetation or landscape on private property (Xu et al., 2019). Additionally, future research should focus on other dimensions of place attachment - e.g., place dependence, place identity (Williams and Vaske, 2003; Raymond et al., 2010; Anton and Lawrence, 2014), sense of place (Davenport and Anderson, 2005), social bonding (Kyle et al., 2005) in forming an opinion about who should decide on tree removal.

Results of our study, suggest that decision-makers regulating the removal of trees on privately owned land should consider the difference between rural and urban regions. This distinction may contribute to greater social acceptance of tree management across a regulatory regime. Decentralization of regulations and other environmental management considerations may avoid possible conflicts of interest in improving environmental management (Maczka et al., 2021). However, this study's results refer to the cases of two municipalities, and there is a need for more extensive studies examining a larger number of cases.

The study results indicate that in tree management, it is crucial not only to perceive the value of trees but also to consider psychological variables related to the opinion of who should decide about tree removal, which is often missed in the preparation of programs on tree management. We recommend that in the future, stakeholders should cooperate with interdisciplinary teams, including psychologists, which will help to provide a holistic approach to solve the problem of tree management and the problem of conflicts between the administration and tree owners.

\section{DATA AVAILABILITY STATEMENT}

The datasets presented in this study can be found in online repositories. The names of the repository/repositories and accession number(s) can be found below: https://osf.io/ksbxw/.

\section{ETHICS STATEMENT}

Ethical review and approval was not required for the study on human participants in accordance with the local legislation and institutional requirements. The patients/participants provided their written informed consent to participate in this study.

\section{AUTHOR CONTRIBUTIONS}

DP-M: conceptualization, literature review, methodology, validation, formal analysis, data curation, writing - original draft, visualization, and funding. PM: conceptualization, literature review, methodology, writing - review and editing, 
data collection, and funding. PJ: methodology, validation, formal analysis, data curation, and writing - original draft. All authors contributed to the article and approved the submitted version.

\section{FUNDING}

This research was funded by the National Science Centre, Poland, grant number 2017/25/B/HS6/00954 and by the Faculty

\section{REFERENCES}

Abd Kadir, M. A., and Othman, N. (2012). Towards a better tomorrow: street trees and their values in urban areas. Proc. Soc. Behav. Sci. 35, 267-274. doi: 10.1016/j.sbspro.2012.02.088

Anton, C. E., and Lawrence, C. (2014). Home is where the heart is: the effect of place of residence on place attachment and community participation. J. Environ. Psychol. 40, 451-461. doi: 10.1016/j.jenvp.2014.10.007

Blanco, J., Sourdril, A., Deconchat, M., Barnaud, C., San Cristobal, M., and Andrieu, E. (2020). How farmers feel about trees: perceptions of ecosystem services and disservices associated with rural forests in south-western France. Ecosyst. Serv. 42:101066. doi: 10.1016/j.ecoser.2020. 101066

Bonaiuto, M., Alves, S., De Dominicis, S., and Petruccelli, I. (2016). Place attachment and natural hazard risk: research review and agenda. J. Environ. Psychol. 48, 33-53. doi: 10.1016/j.jenvp.2016.07.007

Breger, B. S., Eisenman, T. S., Kremer, M. E., Roman, L. A., Martin, D. G., and Rogan, J. (2019). Urban tree survival and stewardship in a state-managed planting initiative: a case study in Holyoke, Massachusetts. Urban For. Urban Green. 43:126382. doi: 10.1016/j.ufug.2019.126382

Brown, G., and Raymond, C. (2007). The relationship between place attachment and landscape values: toward mapping place attachment. Appl. Geogr. 27, 89-111. doi: 10.1016/j.apgeog.2006.11.002

Buchecker, M., and Frick, J. (2020). The implications of urbanization for inhabitants' relationship to their residential environment. Sustainability 12:1624. doi: 10.3390/su12041624

Buta, N., Holland, S. M., and Kaplanidou, K. (2014). Local communities and protected areas: the mediating role of place attachment for pro-environmental civic engagement. J. Outdoor Recre. Tour 5-6, 1-10. doi: 10.1016/j.jort.2014. 01.001

Camacho-Cervantes, M., Schondube, J. E., Castillo, A., and MacGregor-Fors, I. (2014). How do people perceive urban trees? Assessing likes and dislikes in relation to the trees of a city. Urban Ecosyst. 17, 761-773. doi: 10.1007/s11252014-0343-6

Chambers, R., and Leach, M. (1989). Trees as savings and security for the rural poor. World Dev. 17, 329-342. doi: 10.1016/0305-750x(89)90206-4

Chan, K. M., Balvanera, P., Benessaiah, K., Chapman, M., Díaz, S., GómezBaggethun, E., et al. (2016). Opinion: why protect nature? Rethinking values and the environment. Proc. Nat. Acad. Sci. U.S.A. 113, 1462-1465. doi: 10.1073/ pnas. 1525002113

Chan, K. M., Gould, R. K., and Pascual, U. (2018). Editorial overview: relational values: what are they, and what's the fuss about? Curr. Opin. Environ. Sust. 35, A1-A7. doi: 10.1016/j.cosust.2018.11.003

Chappell, E. N., Parkins, J. R., and Sherren, K. (2020). Climax thinking, place attachment, and utilitarian landscapes: implications for wind energy development. Landscape Urban Plann. 199, 1-11. doi: 10.1016/j.landurbplan. 2020.103802

Cundill, G., Bezerra, J. C., De Vos, A., and Ntingana, N. (2017). Beyond benefit sharing: place attachment and the importance of access to protected areas for surrounding communities. Ecosyst. Serv. 28, 140-148. doi: 10.1016/j.ecoser. 2017.03.011

Davenport, M. A., and Anderson, D. H. (2005). Getting from sense of place to place-based management: an interpretive investigation of place meanings and perceptions of landscape change. Soc. Natur. Resour. 18, 625-641. doi: 10.1080/ 08941920590959613 of Psychology and Cognitive Science of Adam Mickiewicz University in Poznań.

\section{ACKNOWLEDGMENTS}

Research assistance by Marcin Mielewczyk is gratefully acknowledged. This work benefited greatly from the comments of two reviewers.

Dei, G. J. (1992). A forest beyond the trees: tree cutting in rural Ghana. Hum. Ecol. 20, 57-88. doi: 10.1007/BF00889696

Devine-Wright, P., and Howes, Y. (2010). Disruption to place attachment and the protection of restorative environments: a wind energy case study. J. Environ. Psychol. 30, 271-280. doi: 10.1016/j.jenvp.2010.01.008

De Vos, A., Bezerra, J. C., and Roux, D. (2018). Relational values about nature in protected area research. Curr. Opin. Environ. Sust. 35, 89-99. doi: 10.1016/j. cosust.2018.10.018

Díaz, S., Demissew, S., Carabias, J., Joly, C., Lonsdale, M., Ash, N., et al. (2015). The IPBES Conceptual Framework-connecting nature and people. Curr. Opin. Environ. Sust. 14, 1-16. doi: 10.1016/j.cosust.2014.11.002

Faccioli, M., Czajkowski, M., Glenk, K., and Martin-Ortega, J. (2020). Environmental attitudes and place identity as determinants of preferences for ecosystem services. Ecol. Econ. 174:106600. doi: 10.1016/j.ecolecon.2020. 106600

Fernandes, C. O., da Silva, I. M., Teixeira, C. P., and Costa, L. (2019). Between tree lovers and tree haters. Drivers of public perception regarding street trees and its implications on the urban green infrastructure planning. Urban For. Urban Green. 37, 97-108. doi: 10.1016/j.ufug.2018.03.014

Gosling, E., and Williams, K. J. (2010). Connectedness to nature, place attachment and conservation behaviour: testing connectedness theory among farmers. J. Environ. Psychol. 30, 298-304. doi: 10.1016/j.jenvp.2010. 01.005

Götmark, F. (2009). Conflicts in conservation: woodland key habitats, authorities and private forest owners in Sweden. Scand. J. For. Res. 24, 504-514. doi: 10.1080/02827580903363545

Haines-Young, R., and Potschin, M. (2013). Common international classification of ecosystem services (CICES): consultation on Version 4, August-December 2012. Eur. Environ. Agen. 1-34.

Hernández, B., Hidalgo, M. C., Salazar-Laplace, M. E., and Hess, S. (2007). Place attachment and place identity in natives and non-natives. J. Environ. Psychol. 27, 310-319. doi: 10.1016/j.jenvp.2007.06.003

Jones, R. E., Davis, K. L., and Bradford, J. (2013). The value of trees: factors influencing homeowner support for protecting local urban trees. Environ. Behav. 45, 650-676. doi: 10.1177/0013916512439409

Jorgensen, B. S., and Stedman, R. C. (2006). A comparative analysis of predictors of sense of place dimensions: attachment to, dependence on, and identification with lakeshore properties. J. Environ. Manag. 79, 316-327. doi: 10.1016/j. jenvman.2005.08.003

Knippenberg, L., de Groot, W. T., van den Born, R. J., Knights, P., and Muraca, B. (2018). Relational value, partnership, eudaimonia: a review. Curr. Opini. Environ. Sust. 35, 39-45. doi: 10.1016/j.cosust.2018.10.022

Kyle, G., Graefe, A., and Manning, R. (2005). Testing the dimensionality of place attachment in recreational settings. Environ. Behav. 37, 153-177. doi: 10.1177/ 0013916504269654

Lewicka, M. (2008). Place attachment, place identity, and place memory: restoring the forgotten city past. J. Environ. Psychol. 28, 209-231. doi: 10.1016/j.jenvp. 2008.02.001

Lewicka, M. (2011). Place attachment: how far have we come in the last 40 years? J. Environ. Psychol. 31, 207-230. doi: 10.1016/j.jenvp.2010.10.001

Low, S. M., and Altman, I. (1992). "Place attachment," in Place Attachment, eds S. M. Low and I. Altman (Boston: Springer), 1-12. doi: 10.1007/978-1-46848753-4_1

Maczka, K., Matczak, P., Jeran, A., Chmielewski, P. J., and Baker, S. (2021). Conflicts in ecosystem services management: analysis of stakeholder 
participation in natura 2000 in poland. Environ. Sci. Poli. 117, 16-24. doi: 10.1016/j.envsci.2021.01.001

Mazumdar, S., Docuyanan, F., and McLaughlin, C. (2000). Creating a sense of place: the Vietnamese-Americans and Little Saigon. J. Environ. Psychol. 20, 319-333. doi: 10.1006/jevp.2000.0170

Millennium Ecosystem Assessment (2005). Ecosystems and Human Well-Being, Volume I: Current States and Trends. Washington, DC: Island Press.

Mincey, S., and Vogt, J. (2014). Watering strategy, collective action, and neighborhood-planted trees: a case study of indianapolis, Indiana, U.S. Arbori. Urban For. 40, 84-95.

Mohapatra, B., and Mohamed, A. R. (2013). Place attachment and participation in management of neighbourhood green space: a place-based community management. Int. J. Sust. Soc. 5:266. doi: 10.1504/ijssoc.2013. 054715

Moskell, C., and Allred, S. B. (2013). Residents' beliefs about responsibility for the stewardship of park trees and street trees in New York City. Landscape. Urban Plan. 120, 85-95. doi: 10.1016/j.landurbplan.2013.08.002

Muradian, R., and Pascual, U. (2018). A typology of elementary forms of humannature relations: a contribution to the valuation debate. Curr. Opin. Environ. Sust. 35, 8-14. doi: 10.1016/j.cosust.2018.10.014

Nowak, D. J., and Greenfield, E. J. (2018). Declining urban and community tree cover in the United States. Urban For. Urban Green. 32, 32-55. doi: 10.1016/j. ufug.2018.03.006

Nowak, D. J., and Greenfield, E. J. (2020). The increase of impervious cover and decrease of tree cover within urban areas globally (2012-2017). Urban For. Urban Green. 49:126638. doi: 10.1016/j.ufug.2020.126638

Park, J. J., and Selman, P. (2011). Attitudes toward rural landscape change in England. Environ. Behav. 43, 182-206. doi: 10.1177/0013916509355123

Perkins, D. D., and Long, D. A. (2002). "Neighborhood sense of community and social capital," in Psychological Sense of Community, eds K. D. Bess, A. T. Fisher, C. C. Sonn, and B. J. Bishop (Boston, MA: Springer), 291-318. doi: 10.1007/ 978-1-4615-0719-2_15

Peng, L., Tan, J., Deng, W., and Liu, Y. (2020). Farmers' participation in community-based disaster management: the role of trust, place attachment and self-efficacy. Int. J. Disaster Risk Reduc. 51:101895. doi: 10.1016/j.ijdrr.2020. 101895

Raymond, C. M., Brown, G., and Weber, D. (2010). The measurement of place attachment: personal, community, and environmental connections. J. Environ. Psychol. 30, 422-434. doi: 10.1016/j.jenvp.2010.08.002

Ryfield, F., Cabana, D., Brannigan, J., and Crowe, T. (2019). Conceptualizing 'sense of place'in cultural ecosystem services: a framework for interdisciplinary research. Ecos. Serv. 36:100907. doi: 10.1016/j.ecoser.2019.100907

Scannell, L., and Gifford, R. (2010). Defining place attachment: a tripartite organizing framework. J. Environ. Psychol. 30, 1-10. doi: 10.1016/j.jenvp.2009. 09.006

Schlager, E., and Ostrom, E. (1992). Property-rights regimes and natural resources: a conceptual analysis. Land Econ. 68:249. doi: 10.2307/3146375

Song, Z., Daryanto, A., and Soopramanien, D. (2019). Place attachment, trust and mobility: three-way interaction effect on urban residents' environmental citizenship behaviour. J. Bus. Res. 105, 168-177. doi: 10.1016/j.jbusres.2019. 08.001

Stålhammar, S., and Thorén, H. (2019). Three perspectives on relational values of nature. Sust. Sci. 14, 1201-1212. doi: 10.1007/s11625-019-00718-4
Stedman, R. C. (2002). Toward a social psychology of place: predicting behavior from place-based cognitions, attitude, and identity. Environ. Behav. 34, 561581. doi: 10.1177/0013916502034005001

Stedman, R. C. (2003). Sense of place and forest science: toward a program of quantitative research. For. Sci. 49, 822-829. doi: 10.1093/forestscience/49.6.822

Suchocka, M., Jankowski, P., and Błaszczyk, M. (2019). Perception of urban trees by Polish tree professionals vs. nonprofessionals. Sustainability 11:211. doi: $10.3390 /$ su11010211

Trentelman, C. K. (2009). Place attachment and community attachment: a primer grounded in the lived experience of a community sociologist. Soci. Natur. Resour. 22, 191-210. doi: 10.1080/08941920802191712

Twigger-Ross, C. L., and Uzzell, D. L. (1996). Place and identity processes. J. Environ. Psychol. 16, 205-220. doi: 10.1006/jevp.1996.0017

Van Veelen, B., and Haggett, C. (2016). Uncommon ground: the role of different place attachments in explaining community renewable energy projects. SociologiaRuralis 57, 533-554. doi: 10.1111/soru.12128

Vermeulen, S. J. (1996). Cutting of trees by local residents in a communal area and an adjacent state forest in Zimbabwe. For. Ecol. Manag. 81, 101-111. doi: 10.1016/0378-1127(95)03656-3

Von Wirth, T., Grêt-Regamey, A., Moser, C., and Stauffacher, M. (2016). Exploring the influence of perceived urban change on residents' place attachment. J. Environ. Psychol. 46, 67-82. doi: 10.1016/j.jenvp.2016.03.001

Verbrugge, L., and van den Born, R. (2018). The role of place attachment in public perceptions of a re-landscaping intervention in the river Waal (The Netherlands). Landscape Urban Plann. 177, 241-250. doi: 10.1016/j. landurbplan.2018.05.011

Walker, A. J., and Ryan, R. L. (2008). Place attachment and landscape preservation in rural New England: a Maine case study. Landscape Urban Plann. 86, 141-152. doi: 10.1016/j.landurbplan.2008.02.001

Williams, D. R., and Vaske, J. J. (2003). The measurement of place attachment: validity and generalizability of a psychometric approach. For. Sci. 49, 830-840. doi: 10.1093/forestscience/49.6.830

Xu, G., Li, Y., Hay, I., Zou, X., Tu, X., and Wang, B. (2019). Beyond place attachment: land attachment of resettled farmers in Jiangsu, China. Sustainability 11:420. doi: 10.3390/su11020420

Yang, S., Zhao, W., Pereira, P., and Liu, Y. (2019). Socio-cultural valuation of rural and urban perception on ecosystem services and human well-being in Yanhe watershed of China. J. Environ. Manag. 251:109615. doi: 10.1016/j.jenvman. 2019.109615

Zwiers, S., Markantoni, M., and Strijker, D. (2018). The role of change-and stabilityoriented place attachment in rural community resilience: a case study in south-west Scotland. Com. Dev. J. 53, 281-300. doi: 10.1093/cdj/bsw020

Conflict of Interest: The authors declare that the research was conducted in the absence of any commercial or financial relationships that could be construed as a potential conflict of interest.

Copyright (C) 2021 Paniotova-Maczka, Matczak and Jabkowski. This is an open-access article distributed under the terms of the Creative Commons Attribution License (CC BY). The use, distribution or reproduction in other forums is permitted, provided the original author(s) and the copyright owner(s) are credited and that the original publication in this journal is cited, in accordance with accepted academic practice. No use, distribution or reproduction is permitted which does not comply with these terms. 